\title{
Current Development of Jumei and Analysis of Its Business Mode
}

\author{
Liu Xueping \\ Engineering Training Center \\ Shenyang Aerospace University \\ Shenyang, China
}

\begin{abstract}
In the 21st Century, as women's pursuit for beauty is constantly increasing accompanied by the rise of ecommerce, Jumei quickly stands out and presents itself in front of women after it was founded in 2010. Jumei, the first time-limited cosmetic sales website in China, has had over $80 \%$ shares of the female cosmetics group-buying market ever since its establishment, which is a miracle of ecommerce marketing presented by group buying. However, with the development and expansion of e-commerce, a series of contradictions and conflicts can still not be avoided at the same time, e.g. powerful competitors, logistics distribution, and a shortage of suppliers, etc. Some suggestions and solutions are put forward aiming at these problems to analyze and solve these problems according to the research of Jumei's business mode.
\end{abstract}

Keywords-Jumei, current development, business mode, innovation

\section{INTRODUCTION}

The rapid development of e-commerce has caused great stir all over the world and online group-buying has been developing in various countries with an astonishing speed. For example, the US Groupon and China's Jumei, etc. have all achieved rapid and surprising benefits and development in the development of emerging e-commerce. A great number of online group-buying modes have been introduced to various countries and become an indispensable demand of modern society. While Jumei is the first and also the largest time-limited cosmetic sales market which adheres to the group-buying pattern and a B2C e-commerce development platform using vertical time-limited group-buying mode. Therefore, we carry out analysis and research of the vertical time-limited groupbuying business mode by taking Jumei as a classic example.

\section{CURRENT SitUATION OF JUMEI AND THE EXISTING PROBLEMS}

\section{A. Analysis of Current Situation}

Jumei has changed from the time-limited group buying of only one discounted products daily to multiple products daily now, and in terms of brand management, it mainly focuses on recommending star products together with selling other products. Its suppliers are agents (regional agents or head agent) and distributors, etc. of Lancome, Inoherb and other brands. Since its establishment in March 2010, Jumei has developed from the beginning when the monthly sales was less than 100,000 yuan to the current scale with monthly sales volume reaching 30 million just in one year relying on word-of-mouth. Many international first-line brands began to cooperate with Jumei, e.g. Lancome and Estee Lauder, etc. From the view of angel investor $\mathrm{Xu}$ Xiaoping, online shopping for cosmetics just happened in recent two years and it is Jumei that has changed people's habits for buying cosmetics.

When customers buy cosmetics from the Internet, what they are afraid of most is that they might buy fake products or defected products. Besides, the delivery channel of cosmetics is not transparent. However, Jumei insists on purchasing products from the brand manufacturers, formal agents and counters both at home and from abroad and other credible suppliers and it even has its own quality inspectors at the Procurement Department. It is the key of cosmetics B2C to let customers have good service experience, and get their trust.

\section{B. How to Find Its Own Competitive Advantages When Faced with Homogenized Competition from Peers in the Same Industry}

It seems that Lefeng.com, which has been focusing on setting up its own brand ever since its establishment, has grasped this last straw. It has been reported that the sales volume of Lefeng's own brand JPlus has already accounted for $40 \%$ of the whole sales volume. And according to Wang Licheng, in the future, Lefeng will pay more attention to its own brand. While Jumei, with brand agents as its main business, also launched its own brand in 2012 and began to expand to high-margin businesses. However, analysts told reporters of this journal that after this battle, both Jumei and Lefeng have exposed their ambition to be the leader in this industry, but before the final decisive moment of the comprehensive battle between e-commerce dealers arrives, it is still early to say who the winner is. Some personage in this industry has pointed out that when there is still not a foregone conclusion on the market, visionary vertical e-commerce dealers should focus their attention on building their own business modes and core advantages instead of staring at opponents in hot pursuit. 
TABLE 1 TRADING VOLUME RANKS OF CHINA's B2C BEAUTY AND HEALTHCARE WEBSITES IN 2012

\begin{tabular}{|l|l|l|l|}
\hline rank & $\begin{array}{l}\text { Website's } \\
\text { Name }\end{array}$ & $\begin{array}{l}\text { Trading Volume } \\
\text { in 2012 (100 } \\
\text { million yuan) }\end{array}$ & $\begin{array}{l}\text { Turnover } \\
\text { Growth } \\
\text { Rate in } \\
2012\end{array}$ \\
\hline 1 & Jumei & 18.0 & $350.0 \%$ \\
\hline 2 & Lefeng.com & 14.8 & $134.9 \%$ \\
\hline 3 & Tiantian.com & 7.0 & $100.0 \%$ \\
\hline
\end{tabular}

\section{The Supplier Problem is Still a Huge Difficult Problem Jumei Needs to Face}

Cosmetics are characterized by high gross margin, complex product sources and a great amount of highly imitated and fake products. It is very difficult for startups to establish cooperation with major brands directly, so they can only get products through channels like agents first, but $\mathrm{Chen} \mathrm{Ou}$ is very clear that for a better development of the company, they must give customers $100 \%$ guarantee for authentic products. On one hand, Chen $\mathrm{Ou}$ organized a team made up of a dozen of people to inspect the product bottle by bottle and on the other hand, he promised to customers a 30-day unconditional refund - as long as customers have doubts, even if the already opened or trialused products can be returned directly by the basic customer service, and this service has still not been followed by a second company until now. But so far, their return rate has still remained at about $1 \%$. "You have to believe that most people are users with the shopping needs, while some of the abnormal return is the costs we must pay for in order to provide better service." Chen Ou said.

In the early stage, Chen $\mathrm{Ou}$ has also encountered suppliers of fake products, and his attitude towards them is "to kill without forgiveness". And with the expansion of the website, the sales of more than ten thousand pieces of products within one day makes them get more favor from suppliers. Now, even 100 pieces of La Prairie skin caviar luxe cream, whose unite price for group buying is 1249 yuan, can also be sold out within 5 hours after the group buying begins. Ju Mei can give priority to long-term cooperation with suppliers with good reputation. For example, the cooperation with Kose is arranged by the general manufacturer while for domestic cosmetics brand, try to establish direct cooperation.

But the problem of suppliers is still the most difficult problem $\mathrm{Chen} \mathrm{Ou}$ is faced with, and now some products are often out of stock in the early morning. "We will give priority to those suppliers with the most reliable product sources and then the price. The key to my work is the suppliers, and the second key is also the suppliers, and I hope to establish good control of product supply." Chen Ou said.

\section{Problems with Logistics and Customer Service}

During the great 301 promotion of Jumei, there are more than 15 million UV and at the peak time, there will be more than 1,000 orders. Great network traffic has caused congestion to the pages several times and paralysis of the server. But it is in this case, Jumei has swept away 1 billion yuan just in three days of the Great Promotion of 301 , thus creating a new unsurpassable marketing myth in the promotion of e-business anniversary. Therefore, it is not difficult to imagine that with the logistics explosion and delivery delay, users' complaints are relatively concentrated. The customer hotline has always been busy with logistics complaints and it cannot be connected, so customers might be angry, and even complain the media. We can understand these behaviors.

\section{E. Solutions to Problems and Suggestions}

In the process of analyzing problems with Jumei, I have explored the solutions to problems and future development of Jumei, and summarized some suggestions.

To be professional is the fundamental. After you have understood Jumei's business core operation, you will find that it is just following a simple business logic thought. The main business of Jumei is cosmetics group buying, but because it is the first enterprise to carry out this business with firm and efficient implementation, it has become a very successful enterprise. Therefore, any enterprise can get the opportunity to be professional only if it can find its own business mode, focus on it and cultivate strong professional ability. As opening an online bookstore has created Amazon, online cosmetics group buying has created Jumei.

People-oriented is the core. It is hard to establish a successful enterprise alone, and a team needs to find the correct investor. The astonishing development speed of Jumei has achieved wide attention from the investment field, and it has got the high investment from famous angel investor and the sequoia capital.

Service is the key to success or failure. Well-made website, high-quality and cheap products, reputation and the after-sales service policy of unconditional return within 30 days after opening, etc. All these are the embodiment of Jumei's convenient, reliable and professional service concept and also make Jumei stand out from the various shopping websites. An enterprise must have a strong sense of service and advanced service capacity, and customer relationship management has already become the key to a successful enterprise.

The reason why Jumei can develop rapidly is that it not only borrows some foreign factors, but also combines the preference of China's female customers. Besides, it also understands the development direction of domestic ecommerce, and make constant pursuit for a better and more rapid development. 


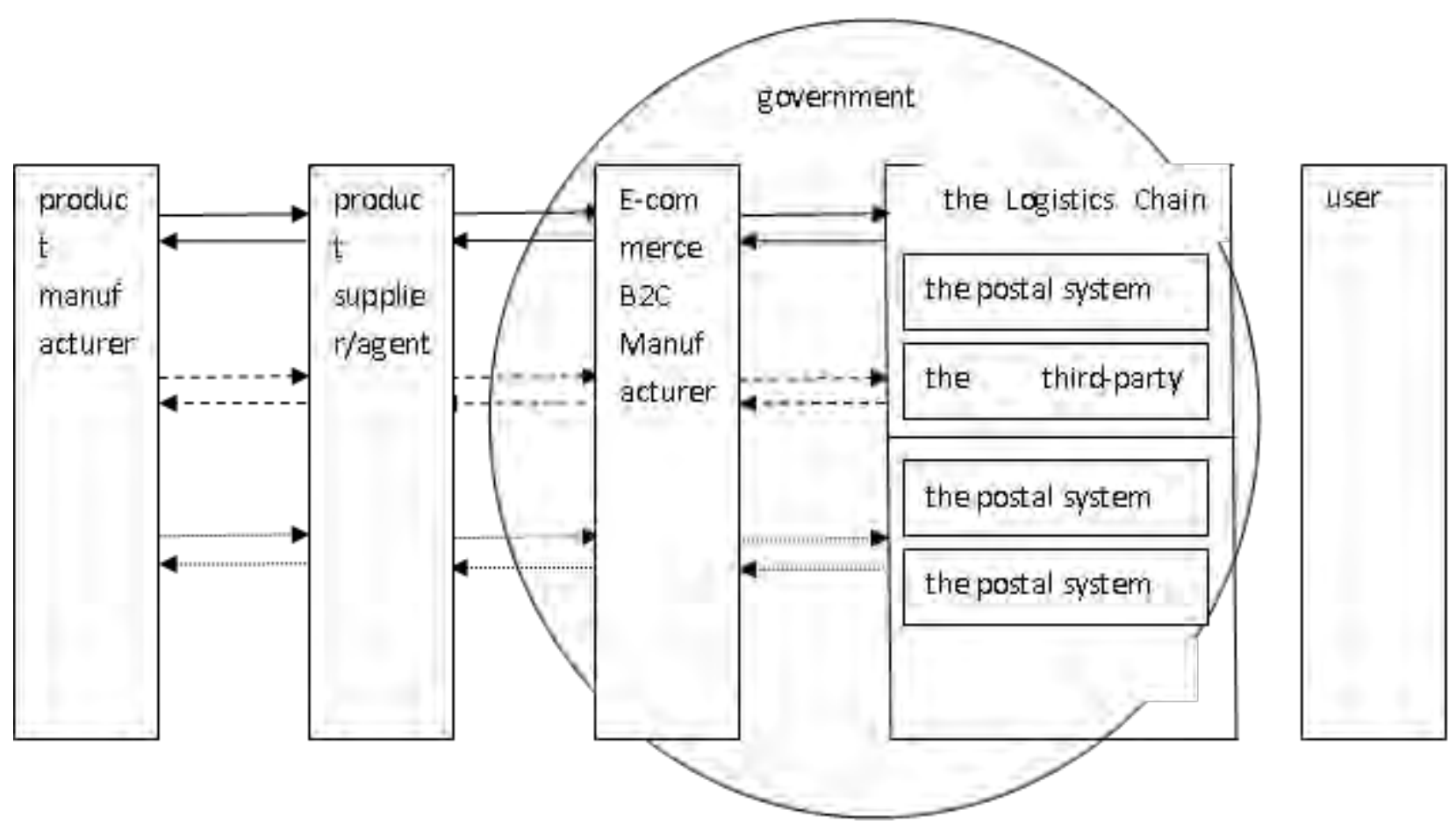

Figure 1. China's B2C E-commerce Industry Chain Structure

\section{BUSINESS MODE OF JUMEI}

\section{A. Introduction to Business Mode}

E-commerce business mode: although the concept of business mode was put forward a long time ago, it has become a topic of wide concern both in theory and practice with the rise of Internet enterprises. Among them, the ecommerce enterprise is the pioneer of the Internet industry and analysis of its business mode has still been the focus of research of many scholars until now. Therefore, it has great practical significance to explore how e-commerce enterprises create values, obtain values and finally make sustainable development through business mode.

1) Business to Business (B2B).

The B2B mode is a business mode based on enterprise date with enterprises as the trading subjects, electronic payment and settlement as the means.

2) Business to Customers (B2C).

The $\mathrm{B} 2 \mathrm{C}$ mode is a mode with the Internet as the main means of service so as to realize public consumption and ensure the relevant electronic payment.

3) Customers to Customers (C2C).

The $\mathrm{C} 2 \mathrm{C}$ mode, commonly known as online auction, is featured with free trade between the ordinary people. In $\mathrm{C} 2 \mathrm{C}$ mode, circulation of goods is realized through the Internet platform, so the buyer and seller in the transaction may be merchants engaged in the retail business (usually small-scaled self-employed), and they may also be ordinary consumers. There is no clear distinction between roles so the logistics is usually two-way and the transaction status can be changed at any time. The main bodies of merchants on the $\mathrm{C} 2 \mathrm{C}$ online shop platform are still individual operators and ordinary consumers, who have relatively weaker strength and reputation, so it is more profitable to gather on the $\mathrm{C} 2 \mathrm{C}$ online shop platform than establishing online shops alone.

\section{B. Development of B2C in the Form of Group Buying}

In terms of China's e-commerce B2C industry chain, it includes five main parts: product manufacturer, product supplier, agent, e-commerce B2C manufacturer, logistics vendors, payment manufacturer and users.

1) Product manufacturer:

The main support in the supply chain. Product manufacturer is at the upper part of the e-commerce B2C market, in charge of the manufacturing of products. The quality of products produced will directly affect users' satisfaction and their cognition and acceptance of ecommerce.

2) Product supplier/agent:

The bridge connecting product manufacturers and ecommerce B2C manufacturers. The product supplier/agent's choice of product and ability to make a decision will directly affect the types and amount of ecommerce B2C industry as well as the influence of ecommerce $\mathrm{B} 2 \mathrm{C}$ website. Both product supplier/agent and manufacturers are at the upper part of the e-commerce $\mathrm{B} 2 \mathrm{C}$ industry chain.

\section{3) E-commerce B2C manufacturer:}

The core link of the industry chain. E-commerce B2C manufacturer is the core link of the industry chain and it will not only directly decide the types and quantity of commodities, but also have direct link with participants of the industry chain: the downstream logistics, payment, users, etc. At present, some of the influential e-commerce $\mathrm{B} 2 \mathrm{C}$ manufacturers will directly contact the manufacturers and shorten the delivery time by establishing their own logistics so as to improve the service quality.

4) The Logistics 
Payment Link: the promoter of cash flow. Currently, China's B2C e-commerce payment mainly includes the ebank payment and payment through the third-party payment platform. Some of the manufacturers adopt the form of cash on delivery, which has formed a tight combination with logistics.

\section{Word-of-Mouth Marketing Development}

Word-of-mouth is probably the oldest marketing tool. Currently, as competition in the market is becoming excessive and credibility of mass media becomes to decline, word-of-moth gradually becomes the best media for enterprises and an effective means to improve the operating performance with its advantages of credibility, low-cost, interactive and effectiveness.

Word-of-mouth communication refers to an informal interpersonal communication about products, brands, organizations and service and between the senders and receivers, who have the ability to sense the specific information.

Although the Internet has brought a lot of new features and more convenient ways of marketing to modern marketing, it dose not weaken the effect of word-of-mouth marketing. Instead, it has the effects of word-of-mouth marketing more outstanding and the spreading speed becomes faster. It is the word-of-mouth marketing method that Jumei has used to make itself get the praise and trust of more users, thus making constantly progress in ecommerce.

\section{Leading Service and Powerful Publicity}

Jumei's advertisement featured by Chen Ou has achieved great success and response, and in this paper, the whole advertisement will be deconstructed and analyzed from its core creativity, forms, issuing ways, media and effects, etc. and its success in reflecting characteristics of the times, using rhythms ingeniously, good writing, accurate advertising time as well as issuing plan and making good use of the media, etc. will be analyzed.

At the end of 2012, Jumei's advertisement starred by Chen Ou himself and with him as the UM8 got great response after it was launched on Hunan TV and it has been played on the Youku for more than 4 million times, and was transferred and evaluated by numerous microbloggers. According to its copywriting form, the "Jumei Type" adapted by many netizens was popular for a period of time, and many customers began to focus their attention on Jumei, greatly improving Jumei's brand effect.

Traditionally, there are few advertisements lasting more than one minute on China's TV media, and there are fewer advertisements that last for two minutes. Jumei's advertisement allows the receivers to have a little sense of achievements and be willing to read the information while participating in the design. Thus, the information disseminated will have effect on people. In addition, it can also be designed into articles for daily use, and have the use value instead of just the value of communicating so that people will not dispose the advertisement immediately after they have received it and will put it at home. Therefore, the advertisement will have its influence virtually. People will make reference to the products introduced in it when they have the need so that the advertisement will have its effects. Of course, we can also make the design by using different materials like cloth, wood, metal, etc. They are all feasible and can make adjustment according to the characteristics of the products so as to avoid the simplified "stylized design form" by finding connection between contents and the forms. The most important is to find the accurate position of this connecting point so as to establish the expression accuracy of form to the theme.

\section{CONCLUSION}

After two months of hard work, I have finally finished the paper analyzing the current development of Jumei and its business mode. During the whole process of design, I have also encountered many problems but finally solved them successfully with the help of my teacher and classmates. In the process of continuous learning I fell that:

It is a constant learning process to write papers. In the beginning, I just had a vague understanding of the current development of Jumei and its business mode, but finally, I have got a deep understanding of this question. And I felt the importance of practice to learning: in the past, I just have the understanding of theories without practice, so my understanding of knowledge was not clear enough, but in this time, I truly combined theories with practice.

In a word, through this graduation design, I deeply realized that to do a complete thing well, we need to have a systematic thinking ways and methods, and we must also be patient with the problems to be solved and use the existing resources to enrich ourselves. Meanwhile, I also deeply realized that in dealing with a new thing, we must have an overall consideration and make the next step only after we have finished the previous step so that we can be more effective.

\section{REFERENCES}

[1] Shen Yan. Research of International Game and Cooperation of the Internet [D]. The Central Party School. 2009; 23-56

[2] Yao Guozhang. "E-commerce Development Strategy of Chinese Enterprises". Peking University Press. 2011; 35-87.

[3] Meng Cuilan. Jumei's Online Marketing Strategy [J]. Modern Business. 2013; 98-106

[4] Ma Hui, Zhao Peng. Brief Analysis of the Current Development of China's Vertical B2V Websites and Their Ways [J]. Business Culture (the first half). 2012;10-21

[5] Li Qi. China's E-commerce. Chengdu. Southwestern University of Finance and Economics Press. 2001; 21-33

[6] Wang Jian。 E-commerce. Shanghai. Haitian Press. 2013; 55-64

[7] Cong Yanni. Brief Discussion about Enlightenment from Jume' s Online Marketing Strategy [J]. Da Guan Weekly. 2012. (34) ; 5687

[8] Li Na. On Enterprises' Online Marketing Strategies under the Environment of E-Commerce [J]. Modern Marketing (school edition0. 2012 (12) ;22-41

[9] Chen Yingying. Research of Publicity Strategy of China's New Online Group Buying 2.0 Websites [D]. Northwest University. $2011 ; 65-68$

[10] Wang Yu. Analysis of Group Buying Websites' Business Modes and Innovation Research [D]. Beijing University of Posts and Telecommunications. 2011;26-36

[11] ]Lu Ying analysis [J]. C2C E-commerce development ebay eBay and Taobao. Foshan Science and Technology University (Natural Science Edition) 2007 (1) ; 33-35

[12] Yan Jing. Modes and media-specific research [J] network events opinion formation. Zhengzhou University (Philosophy and Social $\begin{array}{llll}\text { Sciences) } & .2009 & \text { (6) } & \text {; }\end{array}$ 